\title{
AVALIAÇÃO DAS CONDIÇÕES DE OCORRÊNCIA E EXPLOTAÇÃO DO SISTEMA AQÜÍFERO GUARANI EM SÃO CARLOS - SP
}

\author{
Julio Cesar Arantes Perroni ${ }^{1}$ e Edson Cezar Wendland ${ }^{2}$
}

\begin{abstract}
RESUMO
Esse trabalho apresenta uma avaliação das condições de ocorrência e explotação do SAG - Sistema Aqüífero Guarani na área da cidade de São Carlos - SP. A caracterização geométrica das camadas aqüíferas foi obtida por meio da análise integrada de mapas geológicos e dados de sub-superfície relativos aos poços de água. As condições pretéritas e atuais de fluxo da água nas camadas aqüíferas que constituem o SAG foram extraídas de séries históricas de dados de nível potenciométrico a partir de registros de dados operacionais dos poços utilizados no sistema de abastecimento público de água. Os resultados obtidos indicam que, em alguns poços mais antigos e de maior produção, o rebaixamento progressivo do nível potenciométrico superou 30 metros, em 2004. A análise integrada da superfície piezométrica, direções de fluxo e geometria das camadas indica que as principais áreas de recarga situam-se a N e SE da cidade. Uma estrutura geológica (falha) que atravessa a área na direção SE-NW apresenta deslocamento vertical das camadas provocando o soerguimento da zona de recarga localizada SE e a restrição da comunicação hidráulica com a área central da cidade. A estimativa da disponibilidade anual decorrente da recarga natural é comparada ao consumo autorizado pelo órgão gestor estadual, indicando uma situação de explotação não sustentável.
\end{abstract}

Palavras-Chave: Aqüífero Guarani, ocorrência, explotação, recarga, São Carlos

\begin{abstract}
This paper presents the assessment of natural occurrence and exploitation conditions of Guarani Aquifer System in the city of São Carlos - SP, Brazil. Detailed geological map and subsurface data from water wells were used to determine the geometry of geological layers.

The initial and present groundwater flow paths have been deducted from operational data records of water wells used for public water supply. The results indicated that for some of the oldest wells with high yield the withdrawal was greater than 30 meters in the year of 2004. The integrated analysis of piezometric surface, flow path directions and geometry of geological layers shows that there are two distinct recharge areas located at N and SE of the city. One geological structure (fault) which crosses the area in the direction SE-NW presents vertical displacement of the layers, causing the uplift of the recharge zone located at SE and restricts the hydraulic communication with the central area of the city. An estimate of annual water availability due to natural recharge is compared to the authorized annual water consumption which indicates an non sustainable groundwater exploitation scenario.
\end{abstract}

Key-words: Guarani Aquifer, occurrence, exploitation, recharge, São Carlos

\section{INTRODUÇÃO}

Nos últimos 20 anos, diversos autores têm insistente e enfaticamente divulgado idéias ufanistas sobre as condições de ocorrência e potencialidade do SAG - Sistema Aqüífero Guarani (Rebouças (1976), Araújo (1995), Rocha (1996)). As condições de renovação da água são consideradas como seguras por meio da recarga que seria proveniente da borda da bacia onde as formações geológicas apresentam-se aflorantes em superfície.

A cidade de São Carlos-SP, onde cerca de $50 \%$ da água distribuída pelo órgão municipal de saneamento - o SAAE - Serviço Autônomo de Água e Esgoto - é proveniente de poços tubulares, está cercada de áreas de afloramento e, portanto, segundo as idéias prevalentes, estaria localizada no interior da área de recarga. A explotação local do SAG se iniciou há mais de 30 anos e possibilitou o registro de séries históricas de dados operacionais de poços que permitem uma avaliação da evolução do comportamento do aqüífero.

As condições de ocorrência e explotação do SAG em São Carlos - SP apresentam grande similaridade com outras áreas da borda da Bacia do Paraná, onde os estudos, em escala de detalhe, suportados por dados de sub-superfície, como por exemplo, GIARDIN e FACCINI (2004), MACHADO e FACCINI (2004), MACHADO (2005) e MACHADO e UBIRATAN (2005), os quais identificaram estruturas intrusivas, falhamentos e deslocamentos de blocos que resultam em grande complexidade de ocorrência do SAG nas áreas tidas como áreas de recarga.

1(julioperroni@geowater.com.br)

2(ew@sc.usp.br) 


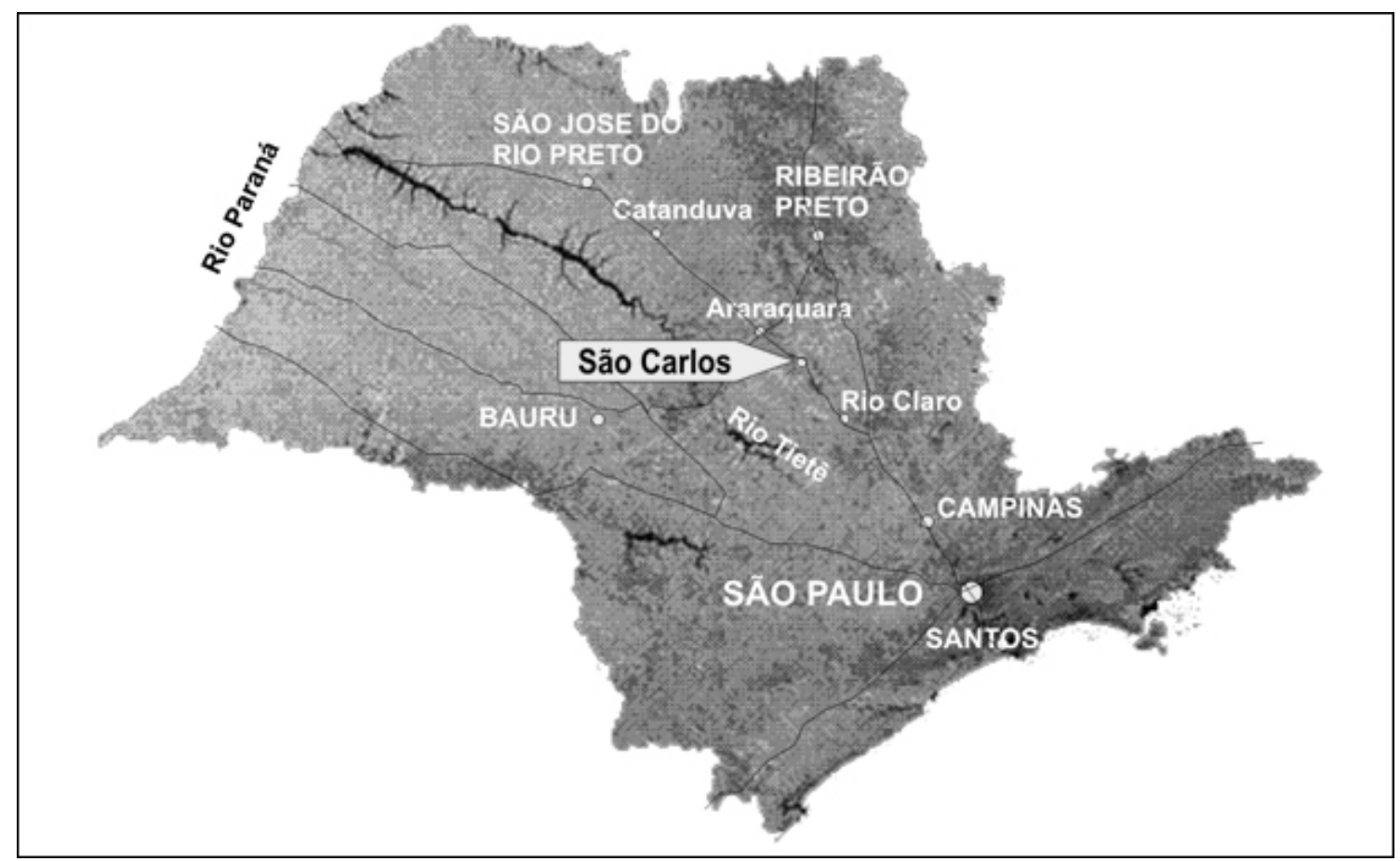

Figura 1 - Mapa de localização da cidade de São Carlos - SP

\section{LOCALIZAÇÃO E CARACTERÍSTICAS GERAIS}

A cidade de São Carlos - SP está localizada no planalto central do Estado de São Paulo, nas coordenadas geográficas $22^{\circ} 21^{\prime} \mathrm{S}$ e $47^{\circ} 54^{\prime} \mathrm{W}$, altitude de $885 \mathrm{~m}$.

Segundo IPT (2004), a cidade de São Carlos faz parte dos $451 \mathrm{~km}^{2}(39,4 \%)$ do município que se encontram inseridos na Bacia do Alto Rio Jacaré-Guaçu, com área de $12.000 \mathrm{~km}^{2}$ e que corresponde à Unidade de Gestão de Recursos Hídricos - UGRHI, número 13 e Comitê da Bacia Hidrográfica Tietê / Jacaré - CBH-TJ. O clima é temperado de altitude (Cwb Koeppen), com média das máximas de $28^{\circ} \mathrm{C}$, média das mínimas de $12^{\circ} \mathrm{C}$, média compensada de $20^{\circ}$ C, umidade relativa no verão de $76 \%$ e inverno de $54 \%$. A pluviosidade média anual varia de 1550 a $1700 \mathrm{~mm}$.

Aárea urbana da sede municipal está contida num perímetro de contorno aproximadamente elíptico, com eixo maior medindo $14 \mathrm{~km}$ na direção NS e eixo menor medindo cerca de 10 $\mathrm{km}$ na direção EO, abrangendo de $95 \mathrm{~km}^{2}$, com uma população estimada, para o ano de 2004, de 200.000 habitantes.

O abastecimento público de água da cidade é feito pelo SAAE - Serviço Autônomo de Água e Esgotos, autarquia municipal. A parcela majoritária da água utilizada no abastecimento (53\%), no ano de 2003, era de origem superficial, captada em dois cursos de água, providos de barragens.

\section{CARACTERIZAÇÃO GEOLÓGICA}

A base de dados utilizada consiste do mapa geológico, em escala 1:25.000, elaborado anteriormente por AGUIAR (1989), levantamento aerofotogramétrico, em escala 1:10.000, elaborado pela BTA ENGENHARIA (1989), dados de sub-superfície e registros históricos de dados operacionais disponíveis dos poços tubulares utilizados pelo SAAE no sistema público de abastecimento de água da cidade.

Na Figura 2 é apresentada a planta geológica simplificada da área da cidade de São Carlos SP, na qual são delimitadas as seguintes unidades litoestratigráficas:

- Grupo Bauru - de idade cretácica superior, correlacionável à Formação Marília, representado por arenitos mal selecionados, castanho claro, médio a grosseiros, imaturos, com níveis conglomeráticos basais, ocorrendo nas partes mais altas do terreno e com espessura máxima de poucas dezenas de metros. A delimitação da área de ocorrência do Grupo Bauru não diferencia as ocorrências de seqüências sedimentares posteriores, como a Formação Itaqueri e sedimentos correlatos da Serra de São Carlos e Santana, mantendo a apresentação do trabalho original de AGUIAR (1989);

- Formação Serra Geral - rochas efusivas do tipo basaltos, com ocorrência nas cotas intermediárias e nos fundos de vale, apresenta 
espessura de até $250 \mathrm{~m}$, podendo apresentar camadas de arenito interderrame, similar ao da formação subjacente (Botucatu);

- Formação Botucatu - arenitos finos a muito finos, muito bem selecionados, constituídos de grãos arredondados de quartzo fosco, com ocorrência nas porções mais baixas da área $\mathrm{e}$ espessura máxima de $200 \mathrm{~m}$. A Fm. Botucatu apresenta uma grande área de afloramento com $53 \mathrm{~km}^{2}$, dominando o setor sul e uma faixa do extremo noroeste. A sua área de ocorrência é predominantemente plana, porém ocorre também em escarpas abruptas e morros testemunho. Em alguns locais apresenta forte silicificação e recristalização, constituindo quartzitos maciços, explorados nos arredores da cidade de São Carlos, para construção civil e pavimentação de passeios públicos;

- Formação Pirambóia - sem afloramentos na área, mas com grandes áreas de exposição a alguns quilômetros a leste do limite do mapa, ocorre em sub-superfície, sendo representada por arenitos finos a grosseiros e até mesmo conglomeráticos, constituídos de grãos subarredondados, hialinos e esbranquiçados, com matriz argilosa. Apresenta em alguns locais, com maior incidência junto ao contato basal, a presença de rochas básicas intrusivas, formando diques e sills de diabásio.

- Formações paleozóicas e embasamento - as perfuraçõesjárealizadasnaáreanãoatravessaram integralmente a seqüência sedimentar, devendo existir, em sub-superfície, diversas centenas de metros de rochas sedimentares das formações paleozóicas da Bacia do Paraná, antes de se atingir o embasamento cristalino da idade précambriana.

\section{Estruturas}

As feições estruturais mais destacadas da área são os lineamentos marcados pela drenagem superficial e alguns contatos geológicos, com direção predominante NW e subordinadamente NE. Segundo Riccomini $(1995,1997)$, em IPT (2004), existem dois feixes de estruturas regionais que se interceptam na área da cidade de São Carlos: um com direção WNW (São Carlos - Leme) e outro de direção NNW (alinhamento do Rio MojiGuaçu). Os perfis litológicos dos poços do SAAE indicam a existência de um falhamento de direção NW, com o bloco rebaixado a NE, na porção SE da área da cidade de São Carlos, conforme indicado na planta (Figura 2). No entanto, o detalhamento da geologia de sub-superfície não foi realizado por extrapolar os objetivos do presente trabalho.
O estudo mais detalhado dos perfis litológicos e geofísicos se faz necessário, para estabelecer as correlações geológicas entre os perfis dos poços (do SAAE e de particulares) e a elaboração de seções geológicas verticais, mapas de isópacas e isóbatas.

\section{CARACTERIZAÇÃO DOS AQÜÍFEROS}

Em função do contexto geológico e dos dados dos poços, são identificados os aqüíferos descritos a seguir:

- Aqüífero Bauru - $\mathrm{O}$ aqüífero é intergranular, livre e semi-confinado, com área de ocorrência, espessura e capacidade restritas e potencial de aproveitamento em poços rasos e de baixa produção. $\mathrm{O}$ contato inferior dos sedimentos com as rochas basálticas propicia a ocorrência de diversas nascentes, na área urbana de São Carlos, as quais são alimentadas por esse aqüífero.

- Aqüífero Serra Geral - O aqüífero é eminentemente fissural, livre e semi-confinado, com forte anisotropia, decorrente da grande variação dos parâmetros hidráulicos da rocha basáltica que, segundo Aguiar (1989), pode apresentar condutividade hidráulica de 1 a 100 $\mathrm{m} / \mathrm{d}$, nas áreas onde se encontra intensamente fraturado e $0,01 \mathrm{~m} / \mathrm{d}$, quando compacto. Esse aqǘfero tem sido bastante explorado na área, em geral de forma conjunta com o aqǘf́ro subjacente (Guarani), em poços parcialmente revestidos, de baixa produção, com grande vulnerabilidade às contaminações bacteriológicas, causadas por fossas sépticas e vazamentos da rede coletora de esgotos. Alguns poços do SAAE, principalmente os mais antigos, atravessam as rochas basálticas e atingem o Aqüífero Guarani e captam os dois aqüíferos simultaneamente (bas/G).

- Sistema Aqüífero Guarani - aqüífero majoritariamente intergranular e eventualmente fissural constituído pelas formações Botucatu e Pirambóia, na área pode se apresentar como livre e semi-confinado.

Os arenitos da Formação Botucatu nas áreas de afloramento, segundo PORTILLO (1988) em AGUIAR (1989), apresentam silicificação dos espaços intersticiais, o que provoca variações da porosidade de $12 \%$ até $1 \%$.

Conforme dados dos ensaios de bombeamento realizados logo após a construção dos poços, os valores da condutividade hidráulica variam de 0,6 a $1,4 \mathrm{~m} / \mathrm{d}$ com média de $0,9 \mathrm{~m} / \mathrm{d}$. O valor médio da vazão específica dos poços existentes é de 5,1 $\mathrm{m}^{3} / \mathrm{h} / \mathrm{m}$. 


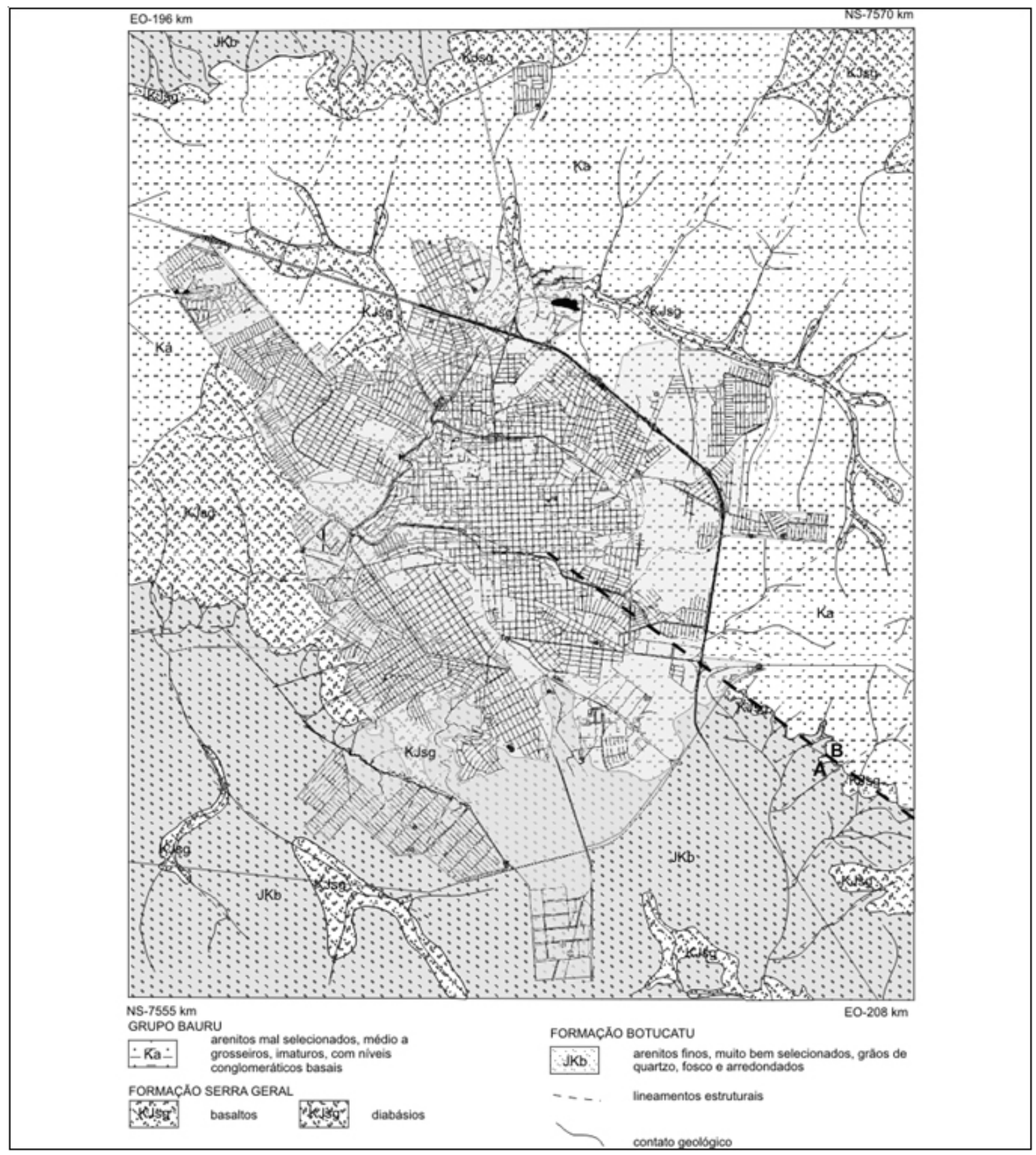

Figura 2 - Planta geológica simplificada da área da cidade de São Carlos-SP (adaptado de Aguiar, 1989).

\section{DADOS DOS POÇOS}

Os 28 poços que eram utilizados, em 2003, no sistema público de abastecimento de água constam da Tabela 1, as suas localizações são indicadas na Figura 3 e possuem as seguintes características:

- 8 poços com profundidade inferior a 200 metros, diâmetro de 6 e 8 polegadas, os quais captam o Aqüífero Serra Geral (fraturas da rocha basáltica e arenito interderrame) podendo captar o Aqüífero Guarani livre (parcialmente);

- 8 poços, com profundidade entre $200 \mathrm{e}$
300 metros, diâmetro de 6 e 8 polegadas os quais captam o Aqüífero Guarani livre; e

- 12 poços, com profundidade total útil de 300 a 480 metros, com câmaras de bombeamento com diâmetros de 10 a 14 polegadas e profundidade de 200 a 300 metros e que captam o Aqüífero Guarani confinado.

Os volumes outorgados de direito de uso de água subterrânea para os poços do SAAE, que não incluíam os poços $\mathrm{n}^{\circ} 16,18,25$ e 27, totalizavam $1.425 \mathrm{mil} \mathrm{m}^{3} /$ mês $\left(1.979 \mathrm{~m}^{3} / \mathrm{h}\right)$. 
Tabela 1 - Dados gerais dos poços tubulares do SAAE.

\begin{tabular}{|c|c|c|c|c|c|c|c|c|c|}
\hline \multirow{2}{*}{$n^{0}$} & \multirow{2}{*}{ nome local } & \multicolumn{2}{|c|}{ coordenada UTM $(\mathbf{k m})$} & \multirow{2}{*}{$\begin{array}{l}\text { cota } \\
(\mathrm{m})\end{array}$} & \multirow{2}{*}{$\begin{array}{l}\text { prof. total } \\
\text { (m) }\end{array}$} & \multirow{2}{*}{$\begin{array}{c}\text { (1) } \\
\text { aqüífero }\end{array}$} & \multicolumn{3}{|c|}{ outorga de uso } \\
\hline & & NS & $\mathrm{EW}$ & & & & $Q(m 3 / h)$ & $\mathrm{h} / \mathrm{dia}$ & $\begin{array}{c}1000 \\
\mathrm{~m}^{3} / \mathrm{mês}\end{array}$ \\
\hline 1 & Água Vermelha I & $7.575,70$ & 200,62 & 820,00 & 68 & G & & & \\
\hline 2 & Antônio Fischer dos Santos & $7.562,06$ & 201,90 & 808,50 & 130 & bas $/ G$ & 52,2 & 19,0 & 29,7 \\
\hline 3 & Novo Horizonte & $7.560,35$ & 205,58 & 891,90 & & $\mathrm{bas} / \mathrm{G}$ & 7,0 & 2,0 & 0,4 \\
\hline 4 & Parque Delta & $7.565,65$ & 200,90 & 850,00 & 151 & bas & & & - \\
\hline 5 & Distrito Industrial MA & $7.559,55$ & 203,62 & 872,80 & 165 & bas/G & 40,0 & 11,5 & 13,8 \\
\hline 6 & Santa Marta I & $7.565,29$ & 200,03 & 821,10 & 172 & bas & & & - \\
\hline 7 & Santa Marta II & $7.565,13$ & 199,85 & 829,30 & 150 & bas & & & - \\
\hline 8 & Samambaia & $7.569,65$ & 202,26 & 834,20 & 167 & G & 15,8 & 12,0 & 5,7 \\
\hline 9 & Maria Stela Fagá & $7.564,70$ & 205,00 & 855,20 & 387 & $\mathrm{Gc}$ & 103,7 & 21,0 & 65,3 \\
\hline 10 & Água Vermelha II & $7.575,76$ & 200,65 & 819,00 & 84 & bas & & & - \\
\hline 11 & Azuville II & $7.561,30$ & 203,98 & 841,10 & 290 & $\mathrm{Gc}$ & 122,2 & 19,0 & 69,6 \\
\hline 12 & São Carlos III & $7.565,38$ & 198,03 & 872,90 & 457 & Gc & 137,1 & 14,0 & 57,6 \\
\hline 13 & Jockey Club I & $7.566,85$ & 200,55 & 862,40 & 235 & Gc & 35,4 & 22,5 & 23,9 \\
\hline 14 & Parque Faber & $7.562,19$ & 198,59 & 814,20 & 213 & bas/G & & & - \\
\hline 15 & Santa Felicia & $7.564,46$ & 198,88 & 864,00 & 465 & $\mathrm{Gc}$ & 260,0 & 20,0 & 156,0 \\
\hline 16 & Boa Vista & $7.560,28$ & 200,86 & 852,90 & 345 & Gc & 215,7 & 20,0 & 129,4 \\
\hline 17 & Cidade Aracy & $7.557,53$ & 200,23 & 807,40 & 393 & Gc & 191,7 & 18,5 & 106,4 \\
\hline 18 & Santa Eudoxia & $7.590,95$ & 210,80 & 650,00 & 208 & G & & & - \\
\hline 19 & Tramer & $7.560,40$ & 205,04 & 890,20 & 300 & $\mathrm{Gc}$ & 30,0 & 5,0 & 4,5 \\
\hline 20 & Vila Nery & $7.563,32$ & 203,78 & 903,90 & 484 & Gc & 264,6 & 20,0 & 158,7 \\
\hline 21 & Cruzeiro do Sul & $7.559,17$ & 201,80 & 863,30 & 293 & G & 118,5 & 18,0 & 64,0 \\
\hline 22 & Parque Fehr & $7.566,70$ & 197,15 & 861,50 & 270 & Gc & 70,0 & 20,0 & 42,0 \\
\hline 23 & Jockey Club II & $7.566,89$ & 200,54 & 862,70 & 356 & Gc & 200,0 & 20,0 & 120,0 \\
\hline 24 & Nova Estância & $7.564,74$ & 202,44 & 870,60 & 479 & Gc & 250,0 & & 150,0 \\
\hline 25 & Douradinho & $7.562,40$ & 206,01 & 920,60 & & G & & & - \\
\hline 26 & Núcleo Habitacional WLS & $7.559,97$ & 202,39 & 843,70 & 277 & G & 130,0 & 20,0 & 78,0 \\
\hline 27 & Água Vermelha III & $7.575,70$ & 200,61 & 824,00 & 255 & G & & & - \\
\hline 28 & Vila Alpes & $7.560,77$ & 203,15 & 877,30 & 292 & G & 250,0 & 20,0 & 150,0 \\
\hline \multicolumn{3}{|c|}{$\begin{array}{l}\text { FONTE: Relatórios das empresas } \\
\text { perfuradoras, coordenadas e } \\
\text { altitude fornecidas pelo SAAE, } \\
\text { explotação outorgada pelo DAEE }\end{array}$} & (1) & $\begin{array}{l}\text { bas } \\
\text { bas/G } \\
\mathrm{G} \\
\mathrm{Gc}\end{array}$ & $\begin{array}{l}\text { basalto } \\
\text { basalto e C } \\
\text { Guarani } \\
\text { Guarani co }\end{array}$ & nfinarani & & & 1.425 \\
\hline
\end{tabular}




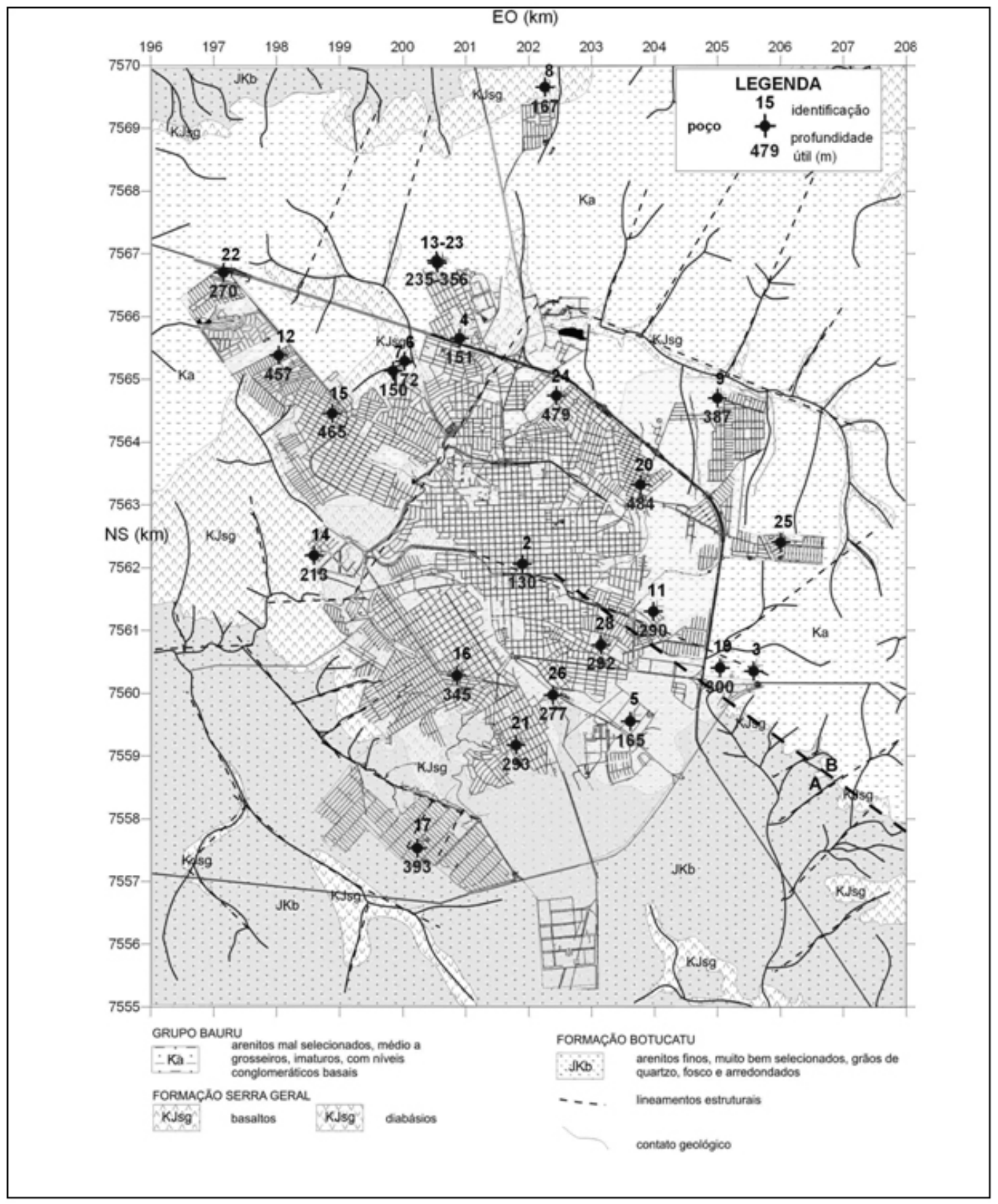

Figura 3 - Planta da área de São Carlos, com representação do substrato geológico, indicação da localização, número de identificação e profundidade útil (m) dos poços do SAAE. 


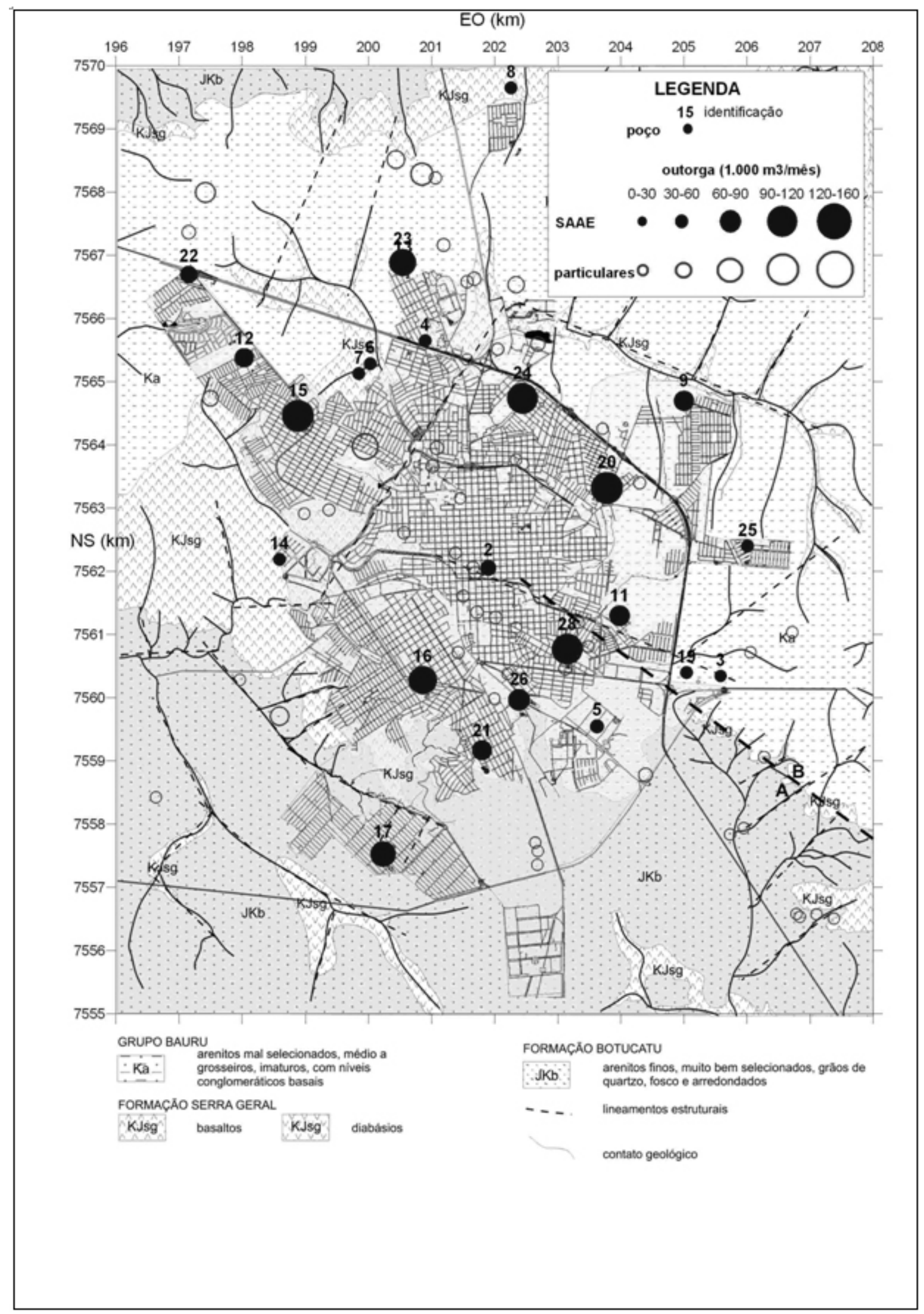

Figura 4 - Planta com indicação das vazões outorgadas de poços públicos e particulares da cidade de São Carlos. Fonte: DAEE - Araraquara. 
A figura 4 apresenta a distribuição espacialdas vazões outorgadaspara cada poço do SAAE, além de 57 poços de sistemas particulares de abastecimento de água que captamo SAG( os quais representam o total de $857 \mathrm{mil} \mathrm{m}^{3}$ mês de direito de uso outorgado, vigente em 02/2004).

As distâncias entre os poços públicos e particulares de alta produção são, em geral, superiores a $1.000 \mathrm{~m}$. No entanto, para vazões menores existem poçosparticulares com direto de uso regularizado, que se encontram muito próximos entre si e próximos também de alguns poços utilizados para abastecimento público, criando situações potenciais de competição e conflito pelo uso da água.

\section{ANÁLISE DA EVOLUÇÃO DO COMPORTAMENTO DO AQÜÍFERO}

A tabela 2 e o gráfico da figura 5 foram elaborados com base nas séries históricas de dados disponíveis de nível estático, no período de 1984 a 2004, e dos ensaios de bombeamento realizados após a construção dos poços. Os dados evidenciam a ocorrência do rebaixamento do nível potenciométrico em quase todos os poços e confirmam as indicações de explotação nãosustentável do aqüífero.

Os dados de nível piezométrico foram utilizados para definir a superfície piezométrica (superfície de tendência), que consta da planta hidrogeológica apresentada na figura 6, onde são também representados: as direções e o sentido do fluxo subterrâneo, gráficos indicativos da produção mensal dos poços (círculos com diâmetro proporcional à produção de água dos poços) e o substrato geológico. A superfície piezométrica e os vetores de fluxo indicam que regionalmente a direção do fluxo da água no SAG se mantém no sentido SE-NW, como originalmente indicou SILVA (1983). No entanto, a explotação de água durante as duas últimas décadas gerou deformações na superfície original, como indicam, por exemplo, as depressões nos poços $n^{\circ}$ 9, 15 e 17. Analisandose em conjunto o gráfico da figura 5 e a planta da figura 6, verifica-se que existe um grupo de poços $\left(n^{\circ} 5,11,19,21\right.$ e 28) em que o nível piezométrico estava originalmente em cotas acima de $770 \mathrm{~m}$, localizado na porção SE da cidade e um segundo grupo de poços $\left(n^{\circ} 9,12,14,22\right.$ e 23$)$ com cotas do nível piezométrico abaixo de $730 \mathrm{~m}$, localizados na área NW da cidade.na área NW da cidade.

Tabela 2 - Variação do nível estático em poços do SAAE a partir de 1970.

\begin{tabular}{|c|c|c|c|c|c|c|c|c|c|}
\hline $\begin{array}{l}\mathrm{n}^{\circ} \text { do } \\
\text { poço }\end{array}$ & nome & UTM EW & UTM NS & aqüífero & \multicolumn{2}{|c|}{ nível es tático $(\mathrm{m})$} & $\begin{array}{c}\text { rebaixamento } \\
(\mathrm{m})\end{array}$ & $\begin{array}{l}\text { idade do } \\
\text { poço (ano) }\end{array}$ & $\begin{array}{c}Q(\mathrm{~m} 3 / \mathrm{h}) \\
\text { média } 2003\end{array}$ \\
\hline 2 & Antônio Fischer dos Santos & 201,90 & $7.562,06$ & $\mathrm{bas} / \mathrm{G}$ & 769 & 737 & 31 & 34 & 48,5 \\
\hline 8 & Samambaia & 202,26 & $7.569,65$ & G & 768 & 763 & 6 & 20 & 18,0 \\
\hline 9 & Maria Stela Fagá & 205,00 & $7.564,70$ & Gc & 710 & 709 & 2 & 17 & 93,1 \\
\hline 14 & Parque Faber & 198,59 & $7.562,19$ & bas/G & 724 & 714 & 11 & 12 & 17,6 \\
\hline 16 & Boa Vista & 200,86 & $7.560,28$ & Gc & 750 & 731 & 19 & 11 & 156,5 \\
\hline 17 & Cidade Aracy & 200,23 & $7.557,53$ & Gc & 743 & 708 & 35 & 9 & 171,6 \\
\hline 19 & Tramer & 205,04 & $7.560,40$ & G & 786 & 778 & 8 & 8 & 22,2 \\
\hline 20 & Vila Nery & 203,78 & $7.563,32$ & Gc & 760 & 736 & 24 & 7 & 286,7 \\
\hline 24 & Nova Estância & 202,44 & $7.564,74$ & Gc & 715 & 717 & (2) & 3 & 285,0 \\
\hline 25 & Douradinho & 206,01 & $7.562,40$ & G & 794 & 777 & 16 & 1 & 49,2 \\
\hline 26 & Núcleo Habitacional WLS & 202,39 & $7.559,97$ & G & 777 & 773 & 4 & 1 & 130,7 \\
\hline 28 & Vila Alpes & 203,15 & $7.560,77$ & G & 794 & 789 & 4 & 0 & 182,2 \\
\hline
\end{tabular}




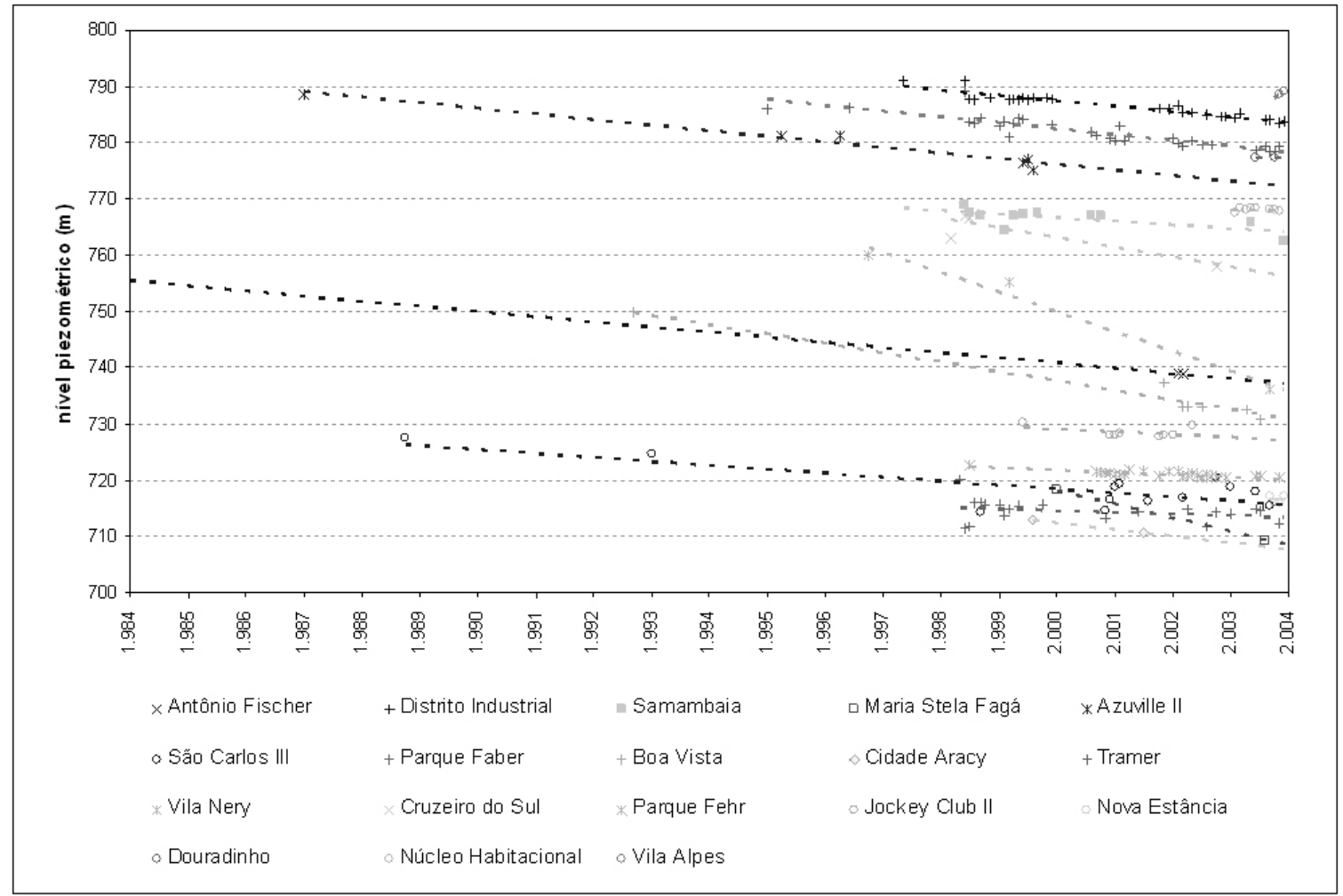

Figura 5 - Gráfico da evolução do nível piezométrico dos poços do SAAE, no período de 1984 a 2004.

O primeiro grupo representa uma importante área de recarga, onde a Fm. Botucatu não aflora e encontra-se recoberta por sedimentos mais recentes, como ocorre no poço $\mathrm{n}^{\mathrm{o}} 26$. Existe uma grande diferença de cota piezométrica entre o lado sudoeste e nordeste de uma estrutura de falha normal, com direção NW-SE. Esse fato é interpretadocomosendodecorrentedecomunicação hidráulica restrita pelo estrangulamento da seção vertical do aqüífero, em sub-superfície, conforme indicado na seção hidrogeológica de direção SWNE apresentada na figura 7.

PFEIFFER \& CHAUDHRY (1993) analisaram amostras da água do SAG em 12 poços da cidade de São Carlos, no entanto não fornecem dados de identificação e localização precisa de modo a permitir a correlação com os poços utilizados no presente trabalho. Foram realizados exames físicos, análises químicas para detecção dos principais cátions e ânions e exames bacteriológicos.

Os resultados obtidos indicaram boas condições de qualidade da água para consumo humano, com baixo teor de sais dissolvidos e pequenas variações de $\mathrm{pH}$, próximo ao neutro. Com exceção dos teores de cálcio, que são muito inferiores aos valores apresentados por SILVA (1983), relativos a 2 poços da cidade de São Carlos, que apresentaram 5 e $6 \mathrm{mg} / \mathrm{L}$, os demais resultados de maneira geral são compatíveis entre os dois trabalhos.

Diversos parâmetros analisados indicaram tratar-se de uma área de recarga do SAG, seja por infiltração direta na área de afloramento da Formação Botucatu, seja pela percolação indireta através das formações Bauru e Serra Geral, com indicações claras da direção e sentido do fluxo subterrâneo de SE para NW.

\section{DISCUSSÃO SOBRE AS CAUSAS DO REBAIXAMENTO}

Com base nos estudos realizados pelo DAEE (1974), PERRONI (2005) derivou uma estimativa da taxa de recarga do SAG de $109 \mathrm{~mm} / \mathrm{ano}$. Segundo AQUA BAVARIA GUARANI (2004), estudos recentes para quantificação da recarga do Aqüífero Guarani, baseados em dados de isótopos naturais e utilizando o modelo de balanço hídrico REGIS concluíram que, na área de afloramento da Fm. Botucatu, em Ribeirão Preto, a taxa de recarga varia entre 200 e $250 \mathrm{~mm} /$ ano.

$\mathrm{Na}$ área da cidade de São Carlos existem áreas de afloramento da Fm. Botucatu, mas predominam áreas onde esta se encontra recoberta por basalto. $\mathrm{Na}$ área urbana existe ainda o efeito da impermeabilização do terreno, resultando em uma recarga potencial muito menor que as mencionadas acima. 


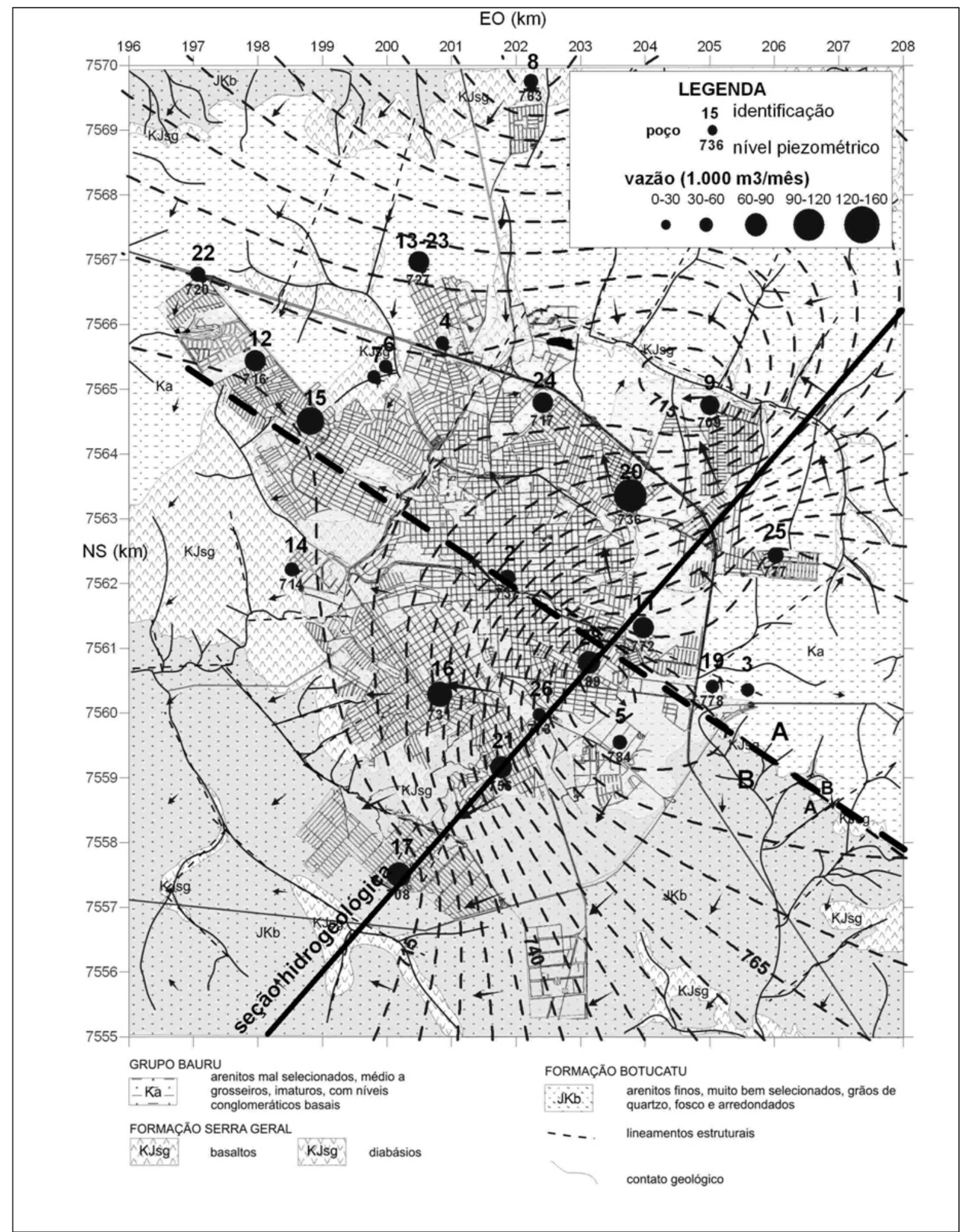

Figura 6 - Superficie piezométrica e direções de fluxo no SAG em São Carlos, em 2003. 


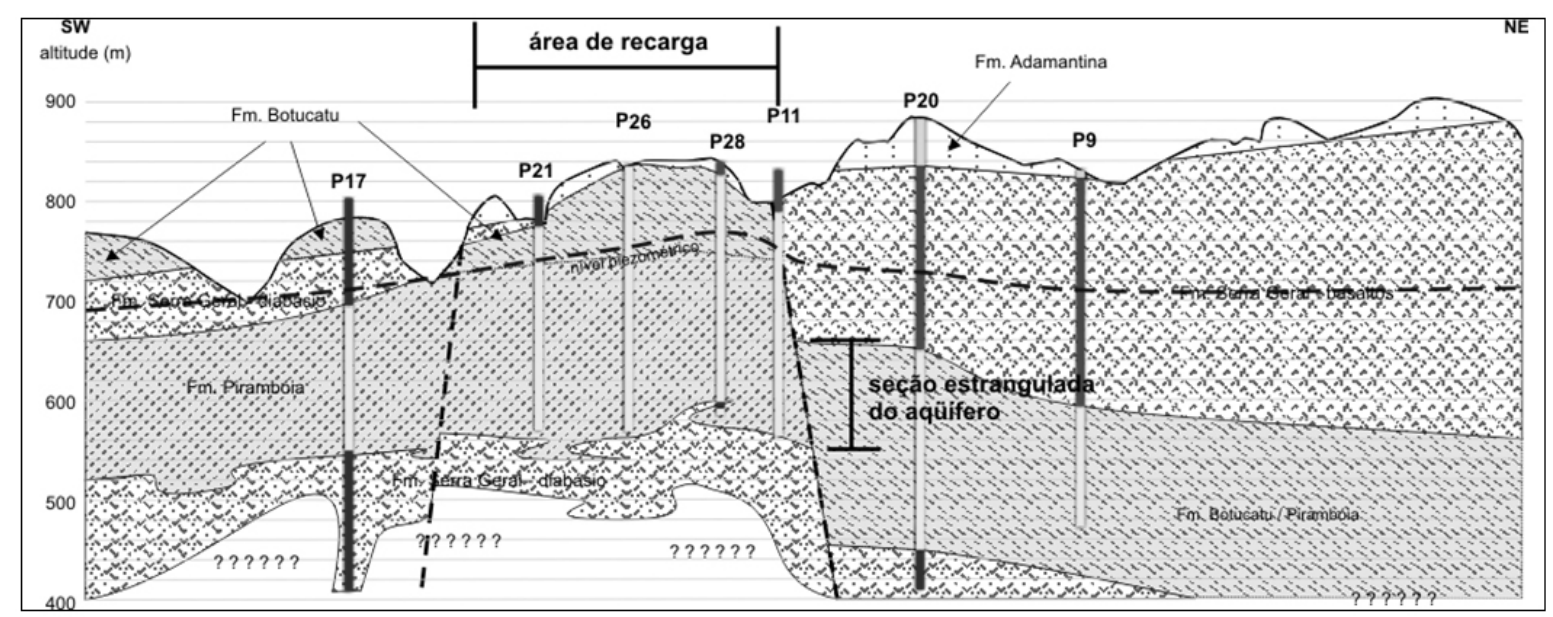

Figura 7 - Seção geológica vertical na direção $S W$-NE, cuja localização é indicada na figura 5, com indicação dos perfis dos poços, nivel piezométrico, área de recarga e seção estrangulada do Aqüifero Guarani.

Para efeito de avaliação preliminar foi considerado o valor de recarga de $100 \mathrm{~mm} / \mathrm{ano}$, resultando no seguinte balanço hídrico:

\begin{tabular}{|c|c|}
\hline \multicolumn{2}{|c|}{ Demanda } \\
\hline - Poços do SAAE & $1.425 \mathrm{~m}^{3} / \mathrm{h}$ \\
\hline - Poços de Particulares & $857 \mathrm{~m}^{3} / \mathrm{h}$ \\
\hline Total & $2.282 \mathrm{~m}^{3} / \mathrm{h}$ \\
\hline
\end{tabular}

\begin{tabular}{|c|c|}
\hline \multicolumn{2}{|c|}{ Disponibilidade } \\
\hline - Taxa de recarga & $100 \mathrm{~mm} / \mathrm{ano}$ \\
\hline $\begin{array}{c}\text { - Área atual de captação } \\
\text { (área urbana) }\end{array}$ & $95 \mathrm{~km}^{2}$ \\
\hline - Disponibilidade total & $1.099 \mathrm{~m}^{3} / \mathrm{h}$ \\
\hline Déficit & $1.183 \mathrm{~m}^{3} / \mathrm{h}$ \\
\hline
\end{tabular}

Os cálculos acima, embora tenham um caráter primário, indicam a possibilidade de que esteja ocorrendo localmente a explotação em regime não-sustentável do SAG, que é analisada adiante.

Por um lado, o rebaixamento poderia ser resultado de uma situação transiente em que o sistema estaria formando um cone de rebaixamento, uma vez que o gradiente hidráulico é necessário para a condução da água das zonas de recarga até os poços. Porém esta situação é pouco provável devido ao longo tempo decorrido desde início da explotação do aqüífero na área.

\section{CONCLUSÕES}

O sistema de abastecimento público de água de São Carlos utiliza atualmente $1.425 \mathrm{mil} \mathrm{m}^{3} / \mathrm{mês}$ de água, provenientes dos poços que captam o SAG. Adicionalmente, existe um número incerto de poços utilizados em sistemas particulares de abastecimento, dos quais uma parcela composta por 57 poços possuia, em 2003, outorga de direito de uso de $857 \mathrm{~m}^{3} / \mathrm{h}$.

A avaliação do SAG em São Carlos indicou que:

1. O nível potenciométrico do aqüífero vem sendo rebaixado progressivamente, alcançando $32 \mathrm{~m}$ no poço mais antigo, ao longo de 35 anos de explotação, ou seja com uma taxa média de $0,9 \mathrm{~m} / \mathrm{ano}$, observada em 14 dos 16 poços analisados. As quedas mais acentuadas do nível ocorreram nos poços de maior vazão (Cidade Aracy, Vila Nery, Maria Stella Fagá, Cruzeiro do Sul e Boa Vista).

2. 10 poços apresentaram redução da vazão bombeada relacionada ao rebaixamento progressivo do nível potenciométrico;

A estimativa de disponibilidade anual de água de recarga por infiltração profunda de água meteórica no SAG na área da cidade de São Carlos equivale a $1.836 \mathrm{~m}^{3} / \mathrm{h}$, insuficiente para atender a demanda atual estimada. A principal área de recarga do SAG na área da cidade de São Carlos SP encontra-se a sul e sudeste do perímetro urbano, em área de intensa expansão com seus processos usuais de impermeabilização do terreno e riscos de contaminação, comprometendo a manutenção das condições naturais de disponibilidade volumétrica e qualitativa da água subterrânea na cidade. 


\section{REFERÊNCIAS}

AGUIAR, R.L. (1989). Mapeamento geotécnico da área de expansão urbana de São Carlos - SP: contribuição ao planejamento. 2v. $127 p+14$ mapas. Dissertação de Mestrado Departamento de Geotecnia. Escola de Engenharia de São Carlos, Universidade de São Paulo, São Carlos. 1989.

AQUA BAVARIA GUARANI (2004). Gerenciamento de aqüíferos. Relatório preparado pelo consórcio de consultores alemães sobre a explotação sustentável do Aqüífero Guarani em Ribeirão Preto (SP). Meio Digital.

ARAÚJO, L.M.; FRANÇA, A.B.; POTTER, P.E. (1995). Aqǘf́ero Gigante do Mercosul no Brasil, Argentina, Paraguai, e Uruguai: mapas hidrogeológicos das formações Botucatu, Pirambóia, Rosário do Sul, Buena Vista, Misiones e Tacuarembó. Universidade Federal do Paraná (UFPR) e Petróleo Brasileiro S.A. (Petrobrás), 16p. e anexos.

BTAEngenharia.(1998).Plantaplanialtimétrica, digitalizada e georreferenciada, em escala 1:10.000 da cidade de São Carlos, com a locação dos poços do SAAE. Arquivo em formato dwg, gravado em CD. 1998.

DAEE - Departamento de Águas e Energia Elétrica. (1974). Estudo de águas subterrâneas - Região Administrativa 6.- Ribeirão Preto. DAEE, São Paulo, 1974, 2 v.

IPT - INSTITUTO DE PESQUISAS TECNOLÓGICAS. (1981). Mapa geológico do Estado de São Paulo (1:500.000).- São Paulo. PT, $2 \mathrm{~V}$.

IPT - INSTITUTO DE PESQUISAS TECNOLÓGICAS.(2004).Diagnósticodasituação atual dos recursos hídricos e estabelecimento de diretrizes técnicas para a elaboração do Plano da Bacia Hidrográfica do Tietê / Jacaré. UGRHI 13. Comitê da Bacia Hidrográfica do Tietê / Jacaré CBH TJ. Fundo Estadual de Recursos Hídricos FEHIDRO. Minuta disponível on line em http:// www.sigrh.sp.gov.br. Acesso em 14/11/2004.

GIARDIN, A. \& FACCINI, U. F. (2004). Complexidade hidroestratigráfica e estrutural do Sistema Aqüífero Guarani: abordagem metodológica aplicada ao exemplo de Santa Maria - RS. Rev. Águas Subterrâneas no 18/ Janeiro 2004.

MACHADO, J.L.F.; FACCINI, U. F. (2004). Compartimentação Estrutural do SAG no Rio
Grande do Sul: características hidrodinâmicas e hidroquímicas (em preparação).

MACHADO, J.L.F., (2005). A verdadeira face do Aquíf́ero Guarani: Mitos e Fatos. ABAS XIV Encontro Nacional de Perfuradores de Poços. II Simpósio de Hidrogeologia do Sudeste

MACHADO, J.L.F. e UBIRATAN, F.F., (2005). Influência dos falhamentos regionais na estruturação do Sistema Aqüífero Guarani no Estado do Rio Grande do Sul. Disponível online em http://www.cprm.gov.br/rehi/congresso/ falha_reg.pdf

PERRONI, J.C.A. (2005). Avaliação do consumo de energia elétrica para produção de água - $O$ caso do abastecimento público da cidade de São Carlos - SP. 145p. Dissertação (Mestrado) - Escola de Engenharia de São Carlos, Universidade de São Paulo.

PFEIFFER, S.C. e CHAUDHRY, F.H. (1993). Caracterização da qualidade das águas do Aqǘfero Botucatu na região urbana de São Carlos SP. In: Congresso Brasileiro de Recursos Hídricos do Cone Sul 10., 1993. ABRH Associação Brasileira de Recursos Hídricos. Gramado - RS. p.510-519. 1993.

REBOUÇAS,A.C., (1976), Recursos hídricos da Bacia do Paraná. São Paulo, Tese de Livre Docência, IGc/USP, 143p., 2 mapas.

ROCHA, G. A. (1996). Mega reservatório de água subterrânea do Cone Sul: bases para uma política de desenvolvimento e gestão: Contribuiçao ao Seminário e Workshop Internacional do Aqüífero Gigante do Mercosul, Curitiba, Paraná, Brasil. Universidade Federal do Paraná (Brasil), Universidad de la República Oriental del Uruguay (Uruguay), Universidad Nacional de La Plata (Argentina), SENASA, International Development Research Centre (Canada), 27p (texto de divulgaçao no evento).

SILVA, R.B.G. (1983). Estudo hidroquímico e isotópico das águas subterrâneas do Aqüífero Botucatu no Estado de São Paulo. Tese de Doutoramento, USP-IG, (133 pg), São Paulo. 1983.

\section{AGRADECIMENTOS}

Os autores agradecem a colaboração, sugestões e orientações da equipe de engenheiros do SAAE - São Carlos, liderado pelo Prof. Dr. Jurandyr Povinelli - Diretor Superintendente. 